\title{
Determinants of high density lipoprotein and total cholesterol in women
}

\author{
J W G YARNELL, JANET MILBANK, CAROLINE L WALKER, ANN M FEHILY, \\ AND T M HAYES \\ From the MRC Epidemiology Unit (South Wales) and Department of Medicine, University Hospital of Wales, \\ Cardiff, $U K$
}

SUMMARY An epidemiological study was carried out among a random sample of women aged 18 to 69 years to examine possible determinants of plasma high density lipoprotein and total cholesterol (HDL-C and T-C). In a multiple regression analysis consumption of alcohol, fatty fish, and parental longevity showed positive associations with HDL-C, which were statistically significant. Smoking habit, sucrose consumption, and a family history of ischaemic heart disease showed significantly negative associations. In contrast, T-C was associated significantly only with age and Quetelet's index of body mass. Five variables having significant associations with HDL-C explained only $8 \%$ of the total variance; in the case of T-C $17 \%$ of the variance was explained by age and body mass.

High density lipoprotein cholesterol (HDL-C) has been proposed as an important independent risk indicator for ischaemic heart disease in $\mathrm{men}^{1-3}$ and in women. ${ }^{4}$ In contrast with total cholesterol (T-C) little is known about its determinants, particularly those related to diet. The object of the present study was to compare the determinants of HDL-C with those of T-C.

\section{Method}

\section{STUDY POPULATION}

A random sample of 894 women aged 18-69 was drawn from the electoral register for a defined geographical area in South Wales (population $38000)$ centred on a light-industrial town. These were invited to attend a local clinic for a clinical examination. Nine who were pregnant were excluded from the final sample.

\section{QUESTIONNAIRE}

A brief medical history was taken from each subject. All married or engaged women were asked about their present or past use of oral contraceptives. Some familial factors that may be inherited were also investigated. Family history of ischaemic heart disease was ranked strongly positive if any first-degree relative was reported to have had a first event before the age of 55 years, weakly positive if over 55 but before 65 , and negative if no such history was reported. Longevity was ranked as follows:
$2=$ both parents surviving to at least $80,1=$ one parent surviving to 80 , and $0=$ neither parent surviving to or having yet reached 80 .

\section{PHYSICAL EXAMINATION}

Anthropometric measurements made by one of three trained observers included height using a Holtain stadiometer, weight in light clothing using an accurate beam balance, and skinfold thickness at four sites using a Harpenden skinfold caliper. Blood pressure was taken using a Hawksley random zero sphygmomanometer by one of two trained observers.

Subjects were seen at daytime and evening clinics from September 1978 to February 1979; 115 subjects were seen at home from March to July 1979. A venous blood sample was taken from each subject with minimum venous stasis.

Before the clinic appointments a six-hour fast had been requested of each subject. The period between each subject's last meal and the appointment was noted. Subjects who had had a meal within six hours of the appointment were termed non-fasting.

\section{LIPID ESTIMATIONS}

Ten millilitres of venous blood were collected into containers with EDTA and plasma was separated, usually within 30 minutes of collection. Plasma was maintained at $4^{\circ} \mathrm{C}$ and precipitation of $\mathrm{LDL}$ and VLDL cholesterol was done within 12 hours of collection (and usually within six hours) by the use of sodium heparin/ $\mathrm{MnCl}_{2}(46 \mathrm{mM})$ by the method of 
Burstein. ${ }^{5}$ HDL-C and T-C were estimated on supernatant and whole plasma respectively by the use of the Liebermann-Burchard reaction (after Watson ${ }^{6}$ ). During the course of the study strict quality control was maintained by the use of pooled plasma standards, duplicate samples presented "blindly" to the laboratory, and consecutive samples taken from 15 healthy volunteers on five occasions over a period of three months. The overall coefficient of variation on the 26 pairs of duplicate samples was $6.1 \%$ for HDL-C and $4.2 \%$ for T-C. The total within-subject variation on the 15 volunteers was $\mathbf{1 1 . 9 \%}$ for HDL-C and $13.9 \%$ for T-C. These latter estimates include the laboratory variation in addition to the intra-subject variation.

\section{NUTRITIONAL METHODS}

Data on the consumption of foods and nutrients were obtained from a questionnaire coded by the use of frequency scores. The questionnaire had been validated for certain nutrients such as cereal and vegetable fibre by using weighed dietary records and was constructed with the help of standard food tables. ${ }^{7}$ Portion sizes were estimated from the Household Food Consumption Survey, ${ }^{8}$ and estimates of nutrient quantities or frequency of consumption of certain foods per week were obtained.

\section{STATISTICAL METHODS}

On the basis of extensive univariate analyses it appeared that up to 20 factors, mainly dietary, were related to plasma concentrations of HDL-C, T-C, or both. The data were then examined by multiple linear regression. The nutritional variables selected were alcohol (expressed in millilitres pure alcohol per week), sucrose, total fat, starch, and total protein (expressed both as grams per week or as a percentage of the total calories per week), cereal and vegetable fibre (expressed in grams per week) and tea, coffee, egg, lard, vegetable oil, garlic, and fatty fish consumption (all expressed in the form of frequency scores). The non-dietary variables were family history of ischaemic heart disease, parental longevity, smoking habit, and hormone use. Smoking habit was ranked from 0 to 5 by increasing cigarette consumption. Hormone use was included as three separate dichotomous variables: use of oral contraceptives, hormone replacement treatment, and treatment with any other hormones.

The model was assumed to be additive with no interactions between the independent variables. A stepwise (forward inclusion) procedure, included in the Statistical Package for Social Scientists system of computer programs, was used to examine the relationships between the selected dependent and independent variables. The variable that explained the greatest amount of variance is the independent variable that entered the model first. The variable that explained the greatest amount of variance in conjunction with the first, was entered next and so on, so that each addition yielded the maximum increase in the proportion of the total variance that was explained.

Although some doubts have been voiced about the use of HDL-C expressed as a percentage of T-C (HDL-C\%), particularly in international comparison, ${ }^{9}$ we included this among the dependent variables because of its importance in the Framingham data. ${ }^{10}{ }^{11}$ In our data HDL-C and T-C were largely independent of each other, and both had similar distributions.

\section{Results}

From a total sample of 885 women eligible for inclusion in the study $819(93 \%)$ underwent clinical examination: $806(91 \%)$ each provided a venous blood sample and $779(88 \%)$ returned completed dietary questionnaires. Limited medical information available for the non-respondents indicated that, as a group, they did not differ significantly from the respondents.

Table 1 shows the distribution of nutrient and food consumption by age.

Most variables show only minor trends with age, but alcohol consumption tends to decrease with age and sucrose consumption tends to increase.

Table 2 shows the distribution of smoking habit, body mass index (Quetelet's), and lipid values by age. Smoking habit is most common in the age group $35-54$, but the number of cigarettes smoked by

Table 1 Mean consumption of nutrients and foods per week by age in study population

\begin{tabular}{lcccc}
\hline $\begin{array}{l}\text { Mean values for } \\
\text { nutrients and foods }(S D)\end{array}$ & $\begin{array}{l}18-34 \text { years } \\
(n=288)\end{array}$ & $\begin{array}{c}35-54 \text { years } \\
(n=306)\end{array}$ & $\begin{array}{c}55-69 \text { years } \\
(n=185)\end{array}$ & $\begin{array}{c}\text { All ages } \\
(n=779)\end{array}$ \\
\hline $\begin{array}{l}\text { Alcohol } \\
\text { mls absubed }\end{array}$ & 23 & 19 & 15 & 19 \\
alcohol/week & $(24)$ & $(24)$ & $(26)$ & $(24)$ \\
Sucrose & 301 & 329 & 361 & 326 \\
(g/week) & $(215)$ & $(217)$ & $(252)$ & $(226)$ \\
Starch & 569 & 536 & 526 & 546 \\
(g/week) & $(280)$ & $(284)$ & $(285)$ & $(283)$ \\
Total fat & 595 & 603 & 658 & 613 \\
(g/week) & $(200)$ & $(210)$ & $(224)$ & $(211)$ \\
Total protein & 364 & 350 & 352 & 356 \\
(g/week) & $(96)$ & $(90)$ & $(93)$ & $(93)$ \\
Cereal fibre & 61 & 56 & 58 & 58 \\
(g/week) & $(36)$ & $(36)$ & $(40)$ & $(37)$ \\
Fatty fish & 0.31 & 0.27 & 0.25 & 0.28 \\
(Mean days taken/week)(0.51) & $(0.40)$ & $(0.65)$ & $(0.51)$ \\
Vegetable oil & 1.16 & 1.17 & 1.05 & 1.14 \\
(Mean days used/week) & $(1.64)$ & $(1.55)$ & $(1.64)$ & $(1.60)$ \\
\hline
\end{tabular}


Table 2 Mean values for smoking habit, body mass index, and lipids by age

\begin{tabular}{|c|c|c|c|c|}
\hline & $\begin{array}{l}18-34 \text { years } \\
(n=300)\end{array}$ & $\begin{array}{l}35-54 \text { years } \\
(n=316)\end{array}$ & $\begin{array}{l}55-69 \text { years } \\
(n=203)\end{array}$ & $\begin{array}{l}\text { All ages } \\
(n=819)\end{array}$ \\
\hline \multicolumn{5}{|l|}{ Smoking habit } \\
\hline $\begin{array}{l}\text { \% Non and } \\
\text { ex-smokers } \\
\text { Mean No } \\
\text { ciogrettes smoked }\end{array}$ & $63 \%$ & $50 \%$ & $63 \%$ & $58 \%$ \\
\hline $\begin{array}{l}\text { cigarettes smoked } \\
\text { by smokers/day } \\
\text { (SD) }\end{array}$ & $\begin{array}{l}18.9 \\
(8.4)\end{array}$ & $\begin{array}{l}18.8 \\
(8.6)\end{array}$ & $\begin{array}{l}16.9 \\
(8.4)\end{array}$ & $\begin{array}{l}18.4 \\
(8 \cdot 5)\end{array}$ \\
\hline \multicolumn{5}{|l|}{ Body mass index } \\
\hline \multirow[t]{2}{*}{$\left(\mathrm{kg} \div \mathrm{m}^{2}\right)$} & $23 \cdot 4$ & $25 \cdot 2$ & $26 \cdot 7$ & $24 \cdot 9$ \\
\hline & (3.8) & $(4 \cdot 8)$ & $(5 \cdot 2)$ & $(4 \cdot 7)$ \\
\hline \multicolumn{5}{|l|}{ Lipid values } \\
\hline HDL-C & $\begin{array}{c}2.07 \\
(0.37)\end{array}$ & $\begin{array}{c}2.09 \\
(0.37)\end{array}$ & $\begin{array}{c}2.07 \\
(0.35)\end{array}$ & $\begin{array}{c}2.08 \\
(0.36)\end{array}$ \\
\hline $\operatorname{lm}_{\mathrm{T}-\mathrm{C}}$ & 6.31 & 7.04 & 7.68 & 6.93 \\
\hline (mmol/l) & $(1 \cdot 14)$ & $(1 \cdot 28)$ & $(1 \cdot 39)$ & $(1 \cdot 37)$ \\
\hline HDL-C\% & 33.7 & $30 \cdot 5$ & $27 \cdot 7$ & 31.0 \\
\hline & $(7 \cdot 7)$ & $(7 \cdot 1)$ & $(6 \cdot 1)$ & $(7 \cdot 4)$ \\
\hline
\end{tabular}

"Lipid values based on 806 subjects.

smokers is slightly fewer in the age groups 55-69. As expected both body mass index and T-C show a consistent tendency to increase with age. HDL-C shows no trend with age.

Univariate tabulations of associations between lipid parameters and independent variables are summarised in tables 3 and 4 . Table 3 shows the values of the Pearson correlation coefficients for the continuously distributed independent variables, and table 4 shows the contingency tables for the discretely distributed variables.

Smoking habit and sucrose consumption show negative associations with HDL-C, while alcohol, fatty fish (herring - "kippers"-mackerel, sardines, etc), and use of vegetable oil show positive associations with HDL-C. In the case of T-C only age and body mass index show strongly positive associations. Sucrose and total fat consumption also show positive associations but to a lesser extent. Finally, in the case of HDL-C expressed as a percentage of T-C (HDL-C\%) age, body mass index, sucrose consumption, family history of ischaemic heart disease, and smoking habit all show negative

Table 3 Pearson correlation coefficients between $H D L-C$, $T-C, H D L-C \%$, and selected variables

\begin{tabular}{lccc}
\hline & $\begin{array}{l}H D L-C \\
(n=683)\end{array}$ & $\begin{array}{l}T-C \\
(n=702)\end{array}$ & $\begin{array}{c}H D L-C \% \\
(n=631)\end{array}$ \\
\hline Age & -0.00 & $0.40^{* * *}$ & $-0.31^{* * *}$ \\
Alcohol & $0.13^{* * *}$ & -0.03 & $0 \cdot 11^{* *}$ \\
Sucrose & $-0.13^{* * *}$ & $0.09^{*}$ & $-0.16^{* * *}$ \\
Starch & 0.02 & -0.03 & 0.04 \\
Total fat & -0.03 & $0.08^{*}$ & $-0.08^{*}$ \\
Total protein & 0.07 & 0.01 & 0.05 \\
Cereal fibre & 0.06 & 0.01 & 0.04 \\
Smoking habit & $-0.15^{* * *}$ & 0.02 & $-0.11^{* *}$ \\
Body mass index & -0.04 & $0.21^{* * *}$ & $-0 \cdot 19^{* * *}$ \\
\hline
\end{tabular}

"p<0.05, "*p<0.01, ***p<0.001.
Table 4 Mean HDL-Cby consumption of fatty fish, use of vegetable oil, family history of ischaemic heart disease, and parental longevity

\begin{tabular}{|c|c|c|c|}
\hline & Mean & $(S D)$ & No \\
\hline \multicolumn{4}{|l|}{ Consumption of fatty fish } \\
\hline Twice weekly or more & $2 \cdot 21$ & $(0 \cdot 30)$ & 18 \\
\hline Once weekly & $2 \cdot 11$ & $(0.36)$ & 78 \\
\hline Monthly & $2 \cdot 11$ & $(0 \cdot 33)$ & 168 \\
\hline Rarely or never & 2.05 & $(0 \cdot 38)$ & 479 \\
\hline \multicolumn{4}{|l|}{ Use of vegetable oil } \\
\hline 3 or more days a week & $2 \cdot 11$ & $(0 \cdot 36)$ & 134 \\
\hline 1 or 2 days a week & $2 \cdot 10$ & $(0 \cdot 36)$ & 158 \\
\hline Monthly & $2 \cdot 11$ & $(0 \cdot 36)$ & 63 \\
\hline Rarely or never & $2 \cdot 03$ & $(0 \cdot 37)$ & 369 \\
\hline \multicolumn{4}{|c|}{$\begin{array}{l}\text { Family history of IHD in } 1 \text { or more } 1 \text { st-degree relatives } \\
\text { aged: }\end{array}$} \\
\hline$\leqslant 54$ years & 2.00 & $(0.33)$ & 117 \\
\hline $64-55$ years & $2 \cdot 10$ & $(0.40)$ & 70 \\
\hline None or $\geqslant 65$ & $2 \cdot 09$ & $(0.36)$ & 607 \\
\hline \multicolumn{4}{|c|}{$\begin{array}{l}\text { Parental longevity } \\
\text { (parental age or age at death) }\end{array}$} \\
\hline Both parents $\geqslant$ & $2 \cdot 24$ & $(0.37)$ & 17 \\
\hline One parent $\geqslant 80$ & $2 \cdot 10$ & $(0.36)$ & 141 \\
\hline Both parents & 2.07 & $(0.36)$ & 632 \\
\hline
\end{tabular}

IHD = Ischaemic heart disease.

associations. Only fatty fish consumption, alcohol intake, and use of vegetable oil appear to be positively associated with this lipid parameter.

Table 5 summarises the results of a series -of multiple regression analyses.

Smoking habit and alcohol consumption together explain $4.4 \%$ of the total variance in the case of HDL-C, but the effects of the variables are in different directions. The remaining variables

Table 5 Accumulative proportion of variance explained for $H D L-C, T-C$, and $H D L-C \%$ by associated variables

\begin{tabular}{|c|c|c|c|}
\hline & $\begin{array}{l}\text { Accumulative } \\
\text { proportion } \\
\text { of variance } \\
\text { explained }\end{array}$ & $\begin{array}{l}\text { Significance } \\
\text { level }\end{array}$ & $\begin{array}{l}\text { Direction of } \\
\text { association }\end{array}$ \\
\hline \multicolumn{4}{|l|}{ HDL-C } \\
\hline Smoking & $2 \cdot 4$ & $* * *$ & - \\
\hline Alcohol & $4 \cdot 4$ & $* *$ & + \\
\hline Sucrose & $5 \cdot 3$ & $* *$ & - \\
\hline Fatty fish & $6 \cdot 2$ & * & + \\
\hline Longevity & $6 \cdot 9$ & $\bullet$ & + \\
\hline Family history of IHD & $7 \cdot 5$ & - & - \\
\hline $\begin{array}{l}\text { Vegetable oil } \\
T-C\end{array}$ & $8 \cdot 0$ & NS & + \\
\hline Age & $16 \cdot 4$ & $* *$ & + \\
\hline Body mass index & $17 \cdot 1$ & $*$ & + \\
\hline Vegetable oil & $17 \cdot 5$ & NS & - \\
\hline Alcohol & $17 \cdot 6$ & NS & - \\
\hline \multicolumn{4}{|l|}{ HDL-C\% } \\
\hline Age & $10 \cdot 4$ & $* * *$ & - \\
\hline Sucrose & $12 \cdot 2$ & $* *$ & - \\
\hline Body mass index & $13 \cdot 5$ & $*$ & - \\
\hline Smoking & $14 \cdot 9$ & $* *$ & - \\
\hline Fatty fish & $15 \cdot 7$ & $\bullet$ & + \\
\hline Vegetable oil & $16 \cdot 3$ & * & + \\
\hline Family history of IHD & $16 \cdot 9$ & $*$ & - \\
\hline
\end{tabular}


tabulated explain only a further $3.6 \%$ of the variance and a further seven variables initially included in the multiple regression on the strength of their univariate associations with HDL-C explained only a further $1.0 \%$ of the total variance. In the case of $\mathrm{T}-\mathrm{C}$ age explained $16.4 \%$ of the total variance. The three additional variables tabulated explained an additional $1.2 \%$ of the variance. An additional eight variables not tabulated explained only a further $0 \cdot 7 \%$ of the variance. The HDL-C\% was explained to the extent of $10.4 \%$ of the total variance by age, and sucrose consumption explained an additional $1.8 \%$ of the variance. In addition to the variables tabulated a further 12 explained only an additional $0.8 \%$ of the variance.

\section{Discussion}

One of the principle objectives of this study was to examine the dietary determinants of HDL-C. Examination of table 1 indicates that intake of certain nutrients and foods was subject to wide fluctuations between individuals (large standard deviations) within this population defined by geographical area. Although most intakes of nutrient are within the range expected from other data, ${ }^{8}$ estimates for the intake of fat and fibre are higher than those reported elsewhere. This may be due to an overestimate of the relevant portion sizes in this sample of women. This is unlikely, however, to invalidate comparisons of women with high and low intakes of these nutrients. Methodological problems associated with the collection of nutritional data have been reviewed extensively. ${ }^{12} 13$

In the multiple regression analyses (table 4) several orderings of the independent variables were used to test the consistency of the important variables. Variables such as use of oral contraceptives, which has a very small non-significant negative association with HDL-C in our data, were included in the initial regressions. Exclusion of non-fasting subjects made no difference to the ordering of the final regressions.

The association between smoking habit and HDL-C has been reported in many studies ${ }^{14-16}$ and may be dose-dependent. ${ }^{17}$ This effect was also noted in the present data. In family studies longevity is associated with $\alpha$-lipoproteinaemia ${ }^{18} \mathrm{~A}$ family history of ischaemic heart disease is associated with increased risk of this condition. ${ }^{19}$

No direct assessment of physical activity was made in this study, although raised plasma concentrations of HDL-C have been shown in certain groups of men reporting fairly strenuous physical activity. ${ }^{20}{ }^{21}$ In the present population women as a group do not experience such a wide range of physical activity as do the men. In our data, after adjustment for smoking habit, there was little correlation between leanness (closely associated with physical activity ${ }^{20}$ ) and HDL-C. The negative association between sucrose consumption and HDL-C has been reported tentatively, ${ }^{22}$ but these investigators did not report findings with respect to T-C. In our data these associations were positive, which had the effect of potentiating the negative association with HDL-C\%. Sucrose consumption expressed either as grams per week or as percentage total calories showed similar associations.

Questionnaire data are usually quoted to substantiate the numerously reported associations between alcohol consumption and HDL-C, ${ }^{22-24}$ and similarly it seems reasonable to assume that fish-eating is a regular although infrequent dietary habit. A possible mechanism for this association is the high proportion of polyunsaturated fatty acids contained in fatty fish. ${ }^{8}$ Experimental fish diets can raise plasma concentrations of HDL-C, ${ }^{25}$ but the present findings raise the possibility that even modest consumption of fatty fish may be associated with higher than average levels of HDL-C.

Finally, it should be noted that the major proportion of the variance in the case of HDL-C remains unexplained by the variables under consideration in this study. Even smoking habit and alcohol consumption explain only a small proportion of the variance in our data but, by contrast with total cholesterol where age explains $16 \%$ of the variance, nutrient and food data do provide a small glimmer of encouragement for those who wish to attempt dietary treatments to alter plasma concentrations of HDL-C.

Particular thanks are due to Mrs Sheila Williams and Miss Elizabeth Reynolds for skilled technical help and to the members of the survey team. The work was supported in part by a grant from the British Heart Foundation.

Reprints from: JWGY, MRC Epidemiology Unit, 4 Richmond Road, Cardiff CF2 3AS.

\section{References}

${ }^{1}$ Gofman JW, Young W, Tandy R. Ischaemic heart disease, atherosclerosis and longevity. Circulation 1966; 34: 679-97.

${ }^{2}$ Miller NE, Thelle DS, Førde OH, Mjos OD. The Tromso Heart Study, high density lipoprotein cholesterol and coronary heart disease. A prospective case-control study. Lancet 1977; i: 965-8.

${ }^{3}$ Goldbourt U, Medalie JH. High density lipoprotein cholesterol and incidence of coronary heart disease. The Israeli Ischaemic Heart Disease Study. Am J Epidemiol 1979; 109: 296-308. 
${ }^{4}$ Gordon T, Castelli WP, Hjortland MC, Kannel WB, Dawber TR. High density lipoprotein as a protective factor against coronary heart disease. Am J Med 1977; 62: 707-14.

${ }^{5}$ Albers JJ, Warnick GR, Johnson N, et al. Quality control of plasma high-density cholesterol measurement methods. Circulation 1980; 62; suppl 4: 9-17.

${ }^{6}$ Watson D. A simple method for the determination of serum cholesterol. Clin Chim Acta 1960; 5: 637-43.

${ }^{7}$ Paul AA, Southgate DAT. McCance and Widdowson's the composition of foods, 4th edn. London: HMSO, 1978.

${ }^{8}$ Ministry of Agriculture, Fisheries and Food. Household food consumption and expenditure: 1979. Annual report of the national food survey committee. London: HMSO, 1981.

${ }^{9}$ Knuiman JT, West CE. HDL-cholesterol in men from thirteen countries. Lancet 1981 ; ii: $367-8$.

${ }^{10} \mathrm{Kannel}$ WB, Castelli WP. Is the total serum cholesterol an anachronism? Lancet 1979; ii: 950-1.

${ }^{11}$ Gordon T. HDL and coronary heart disease. Lancet 1980 ; ii: $1139-40$.

${ }^{12}$ Heady JA. Diets of bank clerks. Development of a method of classifying the diets of individuals for use in epidemiological studies. Journal of the Royal Statistical Society $(A)$ 1961; 124: 336-71.

${ }^{13}$ Marr JW. Individual dietary surveys: Purposes and methods. Wld Rev Nutr Diet 1971; 13: 105-64.

${ }^{14}$ Garrison RJ, Kannel WB, Feinleid M, et al. Cigarette smoking and HDL cholesterol. The Framingham offspring study. Atherosclerosis 1978; 30: 17-25.

${ }^{15}$ Williams P, Robinson D, Bailey A. High-density lipoprotein cholesterol and coronary risk factors in normal men, Lancet 1979; i: 72-5.
${ }^{16}$ Goldbourt U, Medalie JH. Characteristics of smokers, non-smokers and ex-smokers among 10000 adult males in Israel. Am J Epidemiol 1977; 105: 75-86.

${ }^{17}$ Crigui M, Wallace RB, Heiss G, et al. Cigarette smoking and high-density lipoprotein cholesterol. Circulation 1980; 62, suppl 4: 70-6.

${ }^{18}$ Glueck CJ, Gartside PS, Steiner PM, et al. Hyperalphaand hypobeta-lipoproteinemia in octogenarian kindreds. Atherosclerosis 1977; 27: 387-406.

${ }^{19}$ Slack J. Risk factors in coronary heart disease. Lancet 1977; i: 366-7.

${ }^{20}$ Wood PD, Haskell W, Klein $\mathrm{H}$, et al. The distribution of plasma lipoproteins in middle-aged male runners. Metabolism 1976; 25: 1249-57.

${ }^{21}$ Haskell WL, Taylor HL, Wood PD, et al. Strenuous physical activity, treadmill exercise test performance and plasma high-density lipoprotein cholesterol. Circulation 1980; 62, suppl 4: 53-61.

${ }^{22}$ Ernst N, Fisher M, Smith W, et al. The association of high density lipoprotein cholesterol with dietary intake and alcohol consumption. Circulation 1980; 62 suppl 4: 41-52.

${ }^{23}$ Castelli WP, Gordon T, Hjortland MC, et al. Alcohol and blood lipids. The cooperative lipoprotein phenotyping study. Lancet 1977; ii: 153-8.

${ }^{24}$ Berg B, Johansson BG. Effects of alcohol on parameters of liver function, plasma lipid concentrations and lipoprotein patterns. Acta Med Scand 1973; suppl 552: 13-8.

${ }^{25}$ von Lossonczy TO, Ruiter A, Bronsgeest-Schoute HC, van Gent CM, Hermus RJJ. The effect of a fish diet on serum lipids. Am J Clin Nutr 1978; 31: 1340-6. 